\title{
Effects of a Cosmetic Psychotherapy Program using an Integrated Approach with Counseling and Meridian Massage on Hwa-byung Relief for Middle-aged Women
}

Hae-ju Bang*, In-hyuk Choi

Department of Cosmetology Therapy Education, Westminster Graduate School of Theology, Yongin-si, Gyeonggi-do, Korea

Corresponding author: Hae-ju Bang, Department of Cosmetology Therapy Education, Westminster Graduate School of Theology, 20111 Dongbaekjukjeon-daero, Giheung-gu, Yonginsi, Gyeonggi-do 16995, Korea

Tel.: +82534250404

Email: hanil201@naver.com

Received July 7, 2017

Revised October 6, 2017

Accepted November 30, 2017

Published March 30, 2018

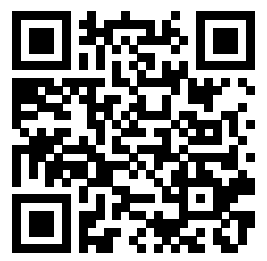

\begin{abstract}
Purpose: The purpose of this study was to develop and apply the beauty psychotherapy program which can reduce the Hwa-byung among the middle-aged women and help to improve their satisfaction and happiness in life. Methods: The subjects of this study are the middle-aged women between 45 and 65 years of age. They underwent experimentation, and meridian counseling, in groups of eight people each, after taking the homogeneity test in accordance with the participation intention. The study was conducted by way of one session a week for 10 weeks. Each session lasting $70 \mathrm{~min}$. This study uses the Kruskal-Wallis test, a nonparametric method, to observe behavioral changes during each session. After conducting experiments among three groups, the statistical data were analyzed using the analysis of variance (ANOVA) method. Results: First, beauty psychotherapy program was efficient in relieving the Hwa-byung among the middle-aged women. Second, according to the changes in each session, the psychological symptoms showed a positive change after the experiment was conducted, compared with those before the experiment. The defense mechanism and correspondence strategy, showed increase in positive ideas about the future. Conclusion: In this study, it was found that the beauty psychotherapy program is effective in mitigating the Hwa-byung among the middle-aged women.
\end{abstract}

Keywords: Beauty psychotherapy, Middle-aged women, Hwa-byung, Meridian massage, Integrated approach

\section{Introduction}

전통적으로 한국 여성은 개인보다는 가족 중심의 생활을 하였 다. 지금의 중년기 여성들은 남편에 대한 내조와 자녀 양육에 큰 역할을 담당하였는데 그에 비해 자신의 자아실현이나 건강에 대 해서는 소홀히 여겨왔다(Park \& Chae, 2001). 자기 자신을 돌 볼 시간적 여유 없이 중년의 나이가 되어 정신적, 육체적으로 쇠 약해진 자신을 돌아보며 지금까지의 삶을 뒤늦게 후회하게 되 는 경우가 많다. 사회에 대한 자신감 부족과 자신에 대한 자존 감 저하로 새로운 삶을 도전하기가 쉽지 않고, 내가 지금 할 수 있는 것이 없다는 자기 자신에게 먼저 화가 나게 되는 경우가 많 다. 자기 자신에 대한 이러한 상실감과 주변 사람들에 대한 서운 함을 가족에게 표현하지 못하고 꾹꾹 억눌러 참고 지내다 보면
화병(火病)으로 이어지는 경우가 빈번히 발생하기도 한다. 이는 한국인의 본성에서 그 요인을 찾을 수 있는데, '자식에 대한 헌 신적인 사랑'과 ‘참는 것이 미덕'이라는 우리의 전통적인 문화와 깊은 관련이 있다(Jo \& Hwang, 2013).

또한 1995년 미국정신의학회에서 발간한 '정신장애의 진단 및 통계 편람 4판' (Diagnostic and statistical manual of mental disorders, DSM-IV)에서는 화병을 한국의 사회문화적 배경을 바탕으로 생겨난 문화 관련 증후군(culture-bound syndrome) 이라고 언급하고 있다(Kim et al., 2013). 결국 화병은 우리민족 의 사회, 문화와 관련된 질병이라 할 수 있다.

화병이란 민간에서 화(火)의 역동성을 상징으로 사용하여 온 병명으로, 울화병이라고도 한다(Chi et al., 1997). 화병의 신체 적 증상으로는 불면증, 피로감, 우울감, 소화불량, 식욕감퇴, 두 
통, 호흡곤란, 가슴 답답함, 속에서 뭔가 올라오는 느낌, 또는 순간적으로 화가 난다거나 가슴에 덩어리가 있다는 느낌 등이 다. 화병은 장기간 누적된 상태에서 억울한 감정이 폭발하여 생 기는 질환이며, 주로 마음이 원인으로 작용하여 발생되는 심신 병으로 한국에서 흔히 볼 수 있는 일종의 분노증후군이다(Park $\&$ Lyu, 1997). 고통스러운 결혼생활, 가난과 고생, 사회적 좌절 그리고 개인의 성격에 의한 속상함, 억울함, 분함, 화남, 증오 등이 그 주된 원인이다(Shin \& Lee, 1998). 일반적으로는 화병 을 심각하게 인식하지 않고 단순히 스트레스로 여겨 자신의 예 민한 성격 탓으로 참고 넘기려 하는 경우가 많다. 따라서 적절한 화병 완화 및 치료 방법에 대한 연구의 필요성이 높아지고 있다.

본 연구자는 효과적인 화병 완화 방법으로 미용심리치료 프로 그램을 제시하였다. 미용치료는 중년여성이 건강한 노후를 맞이 하는데 도움이 되기 위해 정신역학과 심신관계에 개입함으로써 개인들의 삶에 심층적으로 다가서 치료하고자 하는 방법이며, 특히 미용치료의 한 분야인 경락마사지는 정신적 - 신체적 이완 과 자율신경계 조절을 통해 질병의 예방 및 치료뿐만 아니라 스 트레스, 긴장, 분노, 우울, 일상생활의 활력 순으로 치료에 뚜렷
한 효과를 입증하고 있다(Yun \& Shin, 2012). 또한 미용치료에 서 경락마사지를 하기 전에 통합적 접근 기법의 상담을 실시하 여 효과를 극대화시킬 수 있다. 통합적 상담 이론은 인간상담 이 론, 인지 - 행동주의 이론, 게슈탈트(Gestalt) 이론 등을 통합하 여 내담자의 사고, 감정, 행동에 종합적으로 관심을 두고 심리 치료를 하는 관점이다(Lee, 2013). 현재까지 미용으로 스트레 스, 우울증 등을 치료한 사례는 많이 있었으나 미용을 화병에 적 용한 논문은 미비한 실정이기에 통합적 상담 이론에 근거한 미 용심리치료 프로그램을 실시하여 중년여성의 화병 완화에 대한 긍정적 측면을 살펴보고 미용치료의 학문적 기초자료로 제공하 고자 한다.

\section{Methods}

\section{1. 연구대상 및 자료수집}

본 연구는 $\mathrm{D}$ 지역에 거주하는 화병을 가지고 있는 중년여성 (45-65세) 100 명 중에서 질병이나 정신질환의 기왕력이 없으며

\section{Table 1. Psychotherapy program to alleviate Hwa-byung}

\begin{tabular}{|c|c|c|c|c|}
\hline Level & Session & Title & Contents of program & Expected effects \\
\hline \multirow{3}{*}{$\begin{array}{l}<\text { Early }> \\
\text { Creating } \\
\text { rapport }\end{array}$} & 1 & Opening the mind & $\begin{array}{l}\text { After the mind has been opened and rapport has } \\
\text { been produced with hand massage, sharing the } \\
\text { theory and effects of meridian massage. }\end{array}$ & Rapport \\
\hline & 2 & Sharing experiences of anger & $\begin{array}{l}\text { Sharing experiences of anger after hand massage } \\
\text { and showing how to control anger with abdominal } \\
\text { breathing. then relaxing the body and mind with } \\
\text { meridian massage. }\end{array}$ & $\begin{array}{l}\text { Creating rapport and } \\
\text { psychological relaxation }\end{array}$ \\
\hline & 3 & Who am I? & $\begin{array}{l}\text { After promoting client self-awareness relax his or } \\
\text { her body and mind using hand massage, relaxing } \\
\text { the body and mind with meridian massage. }\end{array}$ & Self-awareness \\
\hline \multirow{3}{*}{$\begin{array}{l}<\text { Mid }> \\
\text { Selecting } \\
\text { item for the } \\
\text { agenda }\end{array}$} & 4 & $\begin{array}{l}\text { Who is the source of the } \\
\text { problem? }\end{array}$ & $\begin{array}{l}\text { Talking to client about who is the cause of the } \\
\text { anger, using massaging hands and then teaching } \\
\text { how to express anger without suppressing it, } \\
\text { then, relaxing the body and mind using meridian } \\
\text { massage after relaxing the mind. }\end{array}$ & $\begin{array}{l}\text { Setting up the goal of } \\
\text { therapy }\end{array}$ \\
\hline & 5 & A letter to myself & $\begin{array}{l}\text { Allowing the client peace of mind in writing a } \\
\text { letter to him- or her-self and reading it aloud, then } \\
\text { relaxing the body and mind with meridian massage. }\end{array}$ & $\begin{array}{l}\text { Positive awareness of } \\
\text { the preciousness of } \\
\text { one's own self }\end{array}$ \\
\hline & 6 & Desire & $\begin{array}{l}\text { Having the client promise that he or she will be } \\
\text { the subject for him- or herself, both wishing it and } \\
\text { putting it into action, then relaxing the body and } \\
\text { mind with meridian massage. }\end{array}$ & $\begin{array}{l}\text { Positive self-expression } \\
\text { for change }\end{array}$ \\
\hline \multirow{4}{*}{$\begin{array}{l}<\text { Later }> \\
\text { Practicing } \\
\text { action }\end{array}$} & 7 & Life plan & $\begin{array}{l}\text { Living myself as '00O'. After relaxing the mind of } \\
\text { the client with reconstituted prospects of his or } \\
\text { her new life, relaxing his or her mind and body with } \\
\text { meridian massage. }\end{array}$ & Plan for change \\
\hline & 8 & Me? & $\begin{array}{l}\text { Allowing the client to feel peace of mind, praising } \\
\text { him or herself, creating a new identity, then relaxing } \\
\text { the body and mind with meridian massage. }\end{array}$ & Establishing new identity \\
\hline & 9 & Planning for change & $\begin{array}{l}\text { Sharing how life problems can be coped with, then } \\
\text { relaxing the body and mind with meridian massage. }\end{array}$ & $\begin{array}{l}\text { Setting a goal of detailed } \\
\text { behavior change }\end{array}$ \\
\hline & 10 & Implementation & $\begin{array}{l}\text { Attaining peace of mind by awarding a certificate } \\
\text { to oneself, then relaxing the body and mind with } \\
\text { meridian massage. }\end{array}$ & $\begin{array}{l}\text { Having awareness that } \\
\text { the master of one's life } \\
\text { is oneself }\end{array}$ \\
\hline
\end{tabular}


이와 관련된 약물을 복용한 적이 없는 사람들에게 화병 척도 검 사 설문을 실시하여 총 120 점 이상이 나오고, 맥파계 측정 결과 누적 스트레스가 45 이상으로 집단 간 동질성 검증에 적합한 자 로 선정하였다. 실험집단(통합적 접근 상담과 경락마사지 8명), 비교집단(통합 접근 상담 8명, 경락마사지 8명)으로 구성하여 총 24 명의 연구대상을 확정하였다.

\section{2. 사전 동질성 검사}

본 연구대상인 화병을 가진 중년여성 집단은 실험집단과 비교 집단인 상담집단과 경락집단 3 개의 집단으로 나누어 비모수적 방법인 Kruskal-Wallis 검정으로 사전집단별 동질성, 스트레스 집단 간 동질성을 검증하였다.

\section{3. 연구방법}

1) 미용심리치료 프로그램 진행

중년여성의 화병 완화를 위하여 통합적 접근 상담을 근거로
하여 경락마사지를 이용한 미용심리치료 프로그램을 수행하였 다. 프로그램은 본 연구자의 의견과, 미용관리사, 상담전문가의 평가를 종합하여 과거의 삶을 긍정적으로 재구성하고 방어 대응 전략으로 화에 대응할 수 있도록 구성하였고, 내용은 초기, 중 기, 후기 단계로 구분하였다(Table 1).

미용심리치료 프로그램은 1-10회기까지 주1회, 1 회기 당 시간 은 $70 \mathrm{~min}$ 동안 진행하였다. 프로그램의 구체적 세부내용은 친 밀감 형성, 억압된 감정을 중심으로 통합적 접근 상담을 진행한 이후 경락마사지로 몸과 마음이 이완되도록 하였으며, 효과성을 높이기 위해 회기마다 동일하게 적용하였다(Table 2).

\section{2) 화병 척도 측정}

본 연구에서는 화병 및 스트레스 척도, 신체적 증상 및 대응 전략을 측정하였으며 설문지를 돌려 각 체크 문항 50 을 5 점 리 커트 척도로, '전혀 그렇지 않다' 1점, '그렇지 않은 편이다' 2점, '보통이다' 3점, '그렇다' 4점, '매우 그렇다' 5점으로 구성하였으

Table 2. Beauty psychotherapy program 1 session course and contents

\begin{tabular}{|c|c|c|c|}
\hline \multicolumn{4}{|c|}{ Goal by stage } \\
\hline $\begin{array}{l}\text { Early } \\
\text { period }\end{array}$ & Rapport formation & \multicolumn{2}{|c|}{$\begin{array}{l}\text { Opening the mind with hand massage for rapport formation, and relaxing the body and mind with meridian } \\
\text { massage. }\end{array}$} \\
\hline Session & Subject & Course & Intervention factor \\
\hline 1 & $\begin{array}{l}\text { Opening mind } \\
\text { and goal setting }\end{array}$ & $\begin{array}{l}\text { The description and motivation of the concept of the integrated approach } \\
\text { and meridian massage. The negative emotions regarding marriage are } \\
\text { redefined in terms of Gestalt 'awareness' and expression, and rapport are } \\
\text { formed by means sympathy and support. }\end{array}$ & $\begin{array}{l}\text {-Participation motivation } \\
\text {-Rapport formation }\end{array}$ \\
\hline \multicolumn{2}{|c|}{ Introduction (5 min) } & \multicolumn{2}{|c|}{$\begin{array}{l}\text { Identify the client's world with human-centered counseling. } \\
\text { Listen closely to determine what the main issues facing the client are, what they want and what they are } \\
\text { attempting to obtain support for. } \\
\text { Inform the client of how they can obtain the most benefit from the counseling process. }\end{array}$} \\
\hline \multicolumn{2}{|c|}{$\begin{array}{l}\text { Integrated counseling and } \\
\text { meridian massage (60 min) }\end{array}$} & \multicolumn{2}{|c|}{$\begin{array}{l}\text { Hand massage for intimacy while the counselor says "I love you" and the client calls his or her own name } \\
\text { and says "I love you" this helps rapport building. To open the mind, speak of the client's negative feelings } \\
\text { the he or she has felt in the marriage so far, and use the Gestalt psychotherapy technique termed "here } \\
\text { and now" to recognize emotions and physical reactions. Allow time for the expression of sympathy and } \\
\text { support. } \\
\text { For motivation, make an agreement with the client to make changes with } 10 \text { sessions, as follows; } 1 \text {. I will } \\
\text { change in my self-understanding and ways of coping, 2. I can live a self-directed life after change, and } 3 \text {. I } \\
\text { will live an independent life as the protagonist of my life. } \\
\text { Meridian massage stimulates the autonomic nervous system balancing the parasympathetic and } \\
\text { sympathetic nerves, relieving stress, calming tension, anger, and excitement and facilitating emotional } \\
\text { regulation. If you are positive and are convinced in your mind that meridian massage will relax your } \\
\text { muscles and make your body healthier, you may receive a double effect on your health. } \\
\text { Du meridian: This starts from the back of the neck, with a rubbing of the palm on the vertebrae down to } \\
\text { the lower vertebrae, sweeping it } 14 \text { times-it regulates the flow of energy within the body. } \\
\text { Ren meridian: This sweeps down the meridian (Chun-dol, Chun-jung, Gumi, Geo-gwol, Gi-hae, Gwan-won } \\
\text { Jung-geuk, perineum) } 14 \text { times all the way around, it regulates the flow of energy within the body. } \\
\text { Pericardium meridian: Place your fingers on your thighs and lightly sweep down } 30 \text { times. Put a little } \\
\text { pressure with your thumb on 'Nae-gwan' and 'Tae-reun', shake and hold for } 7 \text { seconds before releasing, } \\
\text { and repeat this action three times. }\end{array}$} \\
\hline \multicolumn{2}{|c|}{ Wrap up (5 min) } & \multicolumn{2}{|l|}{$\begin{array}{l}\text { Speak of your feelings after the session. } \\
\text { If you have any questions, feel free to ask them at any time. } \\
\text { Beforehand, write about the issue to be covered in the next session in your diary. }\end{array}$} \\
\hline \multicolumn{2}{|c|}{ Home care } & \multicolumn{2}{|l|}{$\begin{array}{l}\text { Stretch daily to relax the body. } \\
\text { When the mind is uneasy, perform } 10 \text { abdominal breaths. } \\
\text { Think positive thoughts and read positive content. } \\
\text { Visualize your body and mind getting healthier. }\end{array}$} \\
\hline
\end{tabular}


며 본 연구에서의 신뢰도는 Cronbach's $\alpha=0.93$ 이었다.

\section{3) 맥파에 의한 스트레스 측정}

맥파에 의한 스트레스는 uBioClip (Biosense Creative, Korea)를 이용하여 측정 및 분석하였다. 스트레스지수 해석을 보면 25 이하는 스트레스가 거의 없는 상태이고, 25 이상 35 이하 는 일시적인 스트레스 상태, 35 이상 45 이하는 초기 스트레스 상 태이며, 45 이상 60 이하는 일시적인 스트레스가 반복적으로 쌓 이며 스트레스 내성이 약해지기 시작하는 시기로 본다. 60이상 은 만성스트레스로 진행되기 전 상태로 매우 위험한 지수다.

\section{4) 자료 분석}

본 연구는 수집된 모든 자료는 각 검사의 채점기준에 근거하 여 점수화한 후에 Statistical Package for the Social Sciences (SPSSWIN 12.0; IBM, Korea) 프로그램을 이용하여 세 집단 의 통계적 분석을 진행하였으며, 비모수적 방법인 KruskalWallis 검정을 실시하여 사전집단 간 동질성분석을 진행하였다. 또한 실험집단과 비교집단의 사전 · 사후 분석은 비모수적 방법 인 Wilcoxon 부호 순위 검정을 실시하였다. 실험집단과 비교집 단의 사후 효과 분석은 세 집단의 실험 후 효과 차이분석을 위 해, 일원배치분산분석(analysis of variance, ANOVA)을 실시하 였으며, 각 집단별 사후 검정을 위하여 Bonferroni 검정을 실시 하였다.

\section{5) 회기별 분석}

본 연구에서는 프로그램의 결과 분석에서 통계적 검증에 따른 양적 결과의 신뢰성이 갖는 한계점을 보완하기 위하여, 매 회기 별 인터뷰를 통해 이해하고 기술한 내용을 분석하여 회기별 집
단의 심적 변화 양상에 대한 현상학적 분석을 실시하였다. 이렇 게 분석한 내용을 힘든 감정의 재구조화 과정에 따라 배열하여 개인별 변천기제를 설명하였다. 놓치기 쉬운 내담자의 행동 관 찰, 심리 분석, 일상생활 분석 등 내담자의 치유 및 변화 과정에 서 나타난 현상을 주관적인 경험을 통해 그 속성을 분석하여 본 연구의 효과성을 검증하였다.

\section{Results and Discussion}

\section{1. 중년여성의 화병 특성}

중년여성은 노년기를 눈앞에 두고 있는 상황에서 남편의 외부 활동으로 집안의 경조사나 노년기 부모를 수발해야 하는 부담을 지게 된다. 또한 신체적으로는 폐경과 함께 갱년기 증상을 겪으 며, 이와 함께 사회적으로 요구되는 여성성에 대한 상실을 경험 한다. 그럼으로써, 중년여성은 이제까지 살아온 그들의 삶을 재 평가하고, 자신의 상황에 적합하게 자아상, 생활양식, 가치, 태 도를 변화시키려는 시도를 하게 된다.

심리학에서는 화병이 심리적 스트레스를 겪고 갈등과 체념의 기간을 거치면서 발병하게 되었다고 한다(Kim et al., 1997). 또 한 화병의 원인은 우리나라의 억압 문화와 관련되어 강한 심리 적 스트레스를 억제하는 데에서 기인한다고 설명하였고(Min, 1989), 모든 것이 억울함과 분함이 주된 원인이며, 개인의 인 지적 틀과 스트레스를 지각하는 정도에 따라 더욱 영향을 받는 다고 설명하고 있다(Lim et al., 2000). 화병의 발생 기제는 내 부에 침전된 분노나 원한의 강도가 점점 심해져서 스스로의 힘 으로 통제할 수 없을 경우 화가 깊어지면서 화병으로 발전된다 고 한다. "당신의 화병은 직접적인 원인이 무엇이라고 생각하십

Table 3. Pre-group homogeneity analysis

\begin{tabular}{|c|c|c|c|c|c|c|}
\hline Sub-factor & Group & $\begin{array}{l}\text { Average } \\
\text { ranking }\end{array}$ & $M$ & SD & $x^{2}$ & $p$-value \\
\hline \multirow{3}{*}{ Life evaluation } & Experimental group $(\mathrm{N}=8)$ & 13.13 & \multirow{3}{*}{3.59} & \multirow{3}{*}{0.137} & \multirow{3}{*}{0.973} & \multirow{3}{*}{0.615} \\
\hline & Counseling group $(\mathrm{N}=8)$ & 13.81 & & & & \\
\hline & Meridian group $(\mathrm{N}=8)$ & 10.56 & & & & \\
\hline \multirow{3}{*}{ Psychological symptoms } & Experimental group $(\mathrm{N}=8)$ & 11.13 & \multirow{3}{*}{3.69} & \multirow{3}{*}{0.960} & \multirow{3}{*}{3.201} & \multirow{3}{*}{0.202} \\
\hline & Counseling group $(\mathrm{N}=8)$ & 16.00 & & & & \\
\hline & Meridian group $(\mathrm{N}=8)$ & 10.38 & & & & \\
\hline \multirow{3}{*}{$\begin{array}{l}\text { Defense mechanism and } \\
\text { response strategy }\end{array}$} & Experimental group $(\mathrm{N}=8)$ & 8.88 & \multirow{3}{*}{2.95} & \multirow{3}{*}{0.146} & \multirow{3}{*}{3.918} & \multirow{3}{*}{0.141} \\
\hline & Counseling group $(\mathrm{N}=8)$ & 15.56 & & & & \\
\hline & Meridian group $(\mathrm{N}=8)$ & 13.06 & & & & \\
\hline \multirow{3}{*}{ Physical symptoms } & Experimental group $(\mathrm{N}=8)$ & 13.25 & \multirow{3}{*}{3.69} & \multirow{3}{*}{0.960} & \multirow{3}{*}{0.823} & \multirow{3}{*}{0.663} \\
\hline & Counseling group $(\mathrm{N}=8)$ & 13.56 & & & & \\
\hline & Meridian group $(\mathrm{N}=8)$ & 10.69 & & & & \\
\hline
\end{tabular}

M, mean; S.D., standard deviation. 
니까?”라고 물으면, “제 성격에도 문제가 있습니다.”라는 공감 을 표시한다. 화병에 잘 걸리는 성격으로는 고지식하고 양심적 이며, 항상 감정을 억제하고 뭐든지 “내 탓이오.”라고 인내하는 사람들이라고 할 수 있다. 화병을 주전자라고 비유하면, 뚜껑이 닫혀 있는 주전자에 스트레스를 계속 가할 때 나타나는 반응이 화병입니다. 뚜껑이 열려 있으면 분출되고 하지만 주전자가 낡 았다면 열을 견디지 못하고 터지게 된다. 이렇게 울화된 억울한 감정을 제대로 발산하지 못하고 억지로 참는 가운데 생기는 것 이 화병이다(Kwon \& Choi, 1999).

한은 목, 가슴 증상으로는 가슴속 덩어리, 응어리, 답답함, 한숨, 치밀어 오름, 통증으로는 두통을 위시하여, 관절통, 요 통, 열감으로는 몸과 얼굴이 화끈 달아오름, 더운 느낌, 더위 못 참음 증상들을 '화복합(hwa complex)' 이라고 하였다(Min, 2009).

대부분 일이 힘들거나 커다란 충격을 받았을 때, 가슴이 답답 하고, 숨이 차고, 기운이 없으며 소화가 잘 안 되고 명치에서 목 을 향해 열이 오른다고 한다. 한국 사람들이 흔히 "울화가 치민 다.”라고 표현을 많이 하는데, 오랫동안 참았던 울화, 분노 등이 쌓여 있다가 나이가 들고 정신적 육체적으로 기능이 저하되어 더 이상 참기 어려울 정도로 건강치 못할 때 폭발하면서 다양한 증상으로 나타난다.

\section{2. 사전집단 간 동질성 분석}

사전집단별 및 스트레스집단 간 동질성 분석을 위하여, 비모 수적 방법인 Kruskal-Wallis 검정을 실시하였다. 사전집단별 동질성 분석 결과, 삶의 평가 $\left(\chi^{2}=0.973 ; p=0.615\right)$ 는 사전집단 간 동질한 것으로 나타났으며 $(p>0.05)$, 심리적 증상 $\left(\chi^{2}=3.201\right.$; $p=0.202)$ 또한 사전집단 간 동질한 것으로 나타났다. 방어기
재 및 대응전략 $\left(\chi^{2}=3.918 ; p=0.141\right)$, 신체적 증상 $\left(\chi^{2}=0.823\right.$; $p=0.663)$ 으로 전 하위 요인들의 사전집단은 동질한 것으로 나 타났다(Table 3), 스트레스집단 간 동질성 분석 결과, 맥파계를 활용한 스트레스 지수의 사전집단 간 동질한 것으로 나타났다 $\left(\chi^{2}=5.416 ; p=0.067\right)$ (Table 4).

실험집단과 비교집단의 사전 · 사후 스트레스 차이를 맥파계 로 측정한 결과는 Table 5 와 같다. 실험집단의 스트레스 지수는 유의수준 $(p<0.05)$ 에서 통계적으로 사전집단과 사후집단의 차이 가 있는 것으로 나타났다 $(\mathrm{Z}=2.524 ; p=0.012)$. 실험집단의 경 우 사전보다 사후에 스트레스 지수가 낮아지는 것으로 나타났으 며, 상담집단의 경우 유의수준 $(p<0.05)$ 에서 통계적으로 스트레 스 지수가 사전집단과 사후집단의 차이가 있는 것으로 나타났다 ( $\mathrm{Z}=2.555 ; p=0.011)$. 상담집단의 경우도 상대적으로 사전보다 사후에 스트레스 지수가 낮아지는 것으로 나타났다. 또한, 경락 집단도 유의수준 $(p<0.05)$ 에서 통계적으로 스트레스 지수가 사 전집단과 사후집단의 차이가 있는 것으로 나타났다 $(\mathrm{Z}=2.565$; $p=0.010)$. 경락집단의 경우도 상대적으로 사전보다 사후에 스 트레스 지수가 낮아지는 것으로 나타났다.

실험집단과 상담집단, 경락집단의 실험 후 효과에 대한 차이 분석을 위해, $\mathrm{ANOVA}$ 를 실시하였으며, 각 집단별 사후 검정을 위하여 Bonferroni 검정을 실시하였다. 집단별 스트레스 지수 는 유의수준 $(p<0.05)$ 에서 통계적으로 집단 간 차이가 있는 것으 로 나타났다 $(F=25.44 ; p=0.000)$. 사후 검정 결과, 실험집단과 상담집단, 경락집단에서 차이가 있는 것으로 나타났으며, 실험 집단이 스트레스 지수가 가장 낮았으며, 경락집단, 상담집단 순 으로 나타났다(Table 6).

Table 4. Analysis of homogeneity among stress groups

\begin{tabular}{|c|c|c|c|c|c|c|}
\hline Item & Group & $\begin{array}{l}\text { Average } \\
\text { ranking }\end{array}$ & M & SD & $x^{2}$ & $p$-value \\
\hline \multirow{3}{*}{ Stress index } & Experimental group $(\mathrm{N}=8)$ & 16.75 & \multirow{3}{*}{58.92} & \multirow{3}{*}{5.20} & \multirow{3}{*}{5.416} & \multirow{3}{*}{0.067} \\
\hline & Counseling group $(\mathrm{N}=8)$ & 12.06 & & & & \\
\hline & Meridian group $(\mathrm{N}=8)$ & 8.69 & & & & \\
\hline
\end{tabular}

M, mean; S.D., standard deviation.

Table 5. pre-post analysis of stress in the experimental group and control groups

\begin{tabular}{|c|c|c|c|c|c|}
\hline Group & Division & M & SD & Z & $p$-value \\
\hline \multirow{2}{*}{ Experimental group $(\mathrm{N}=8)$} & Pre-test & 62.38 & 5.63 & \multirow{2}{*}{2.524} & \multirow{2}{*}{$0.012^{*}$} \\
\hline & Post-test & 26.38 & 4.80 & & \\
\hline \multirow{2}{*}{ Counseling group $(\mathrm{N}=8)$} & Pre-test & 58.38 & 3.66 & \multirow{2}{*}{2.555} & \multirow{2}{*}{$0.011^{*}$} \\
\hline & Post-test & 41.38 & 3.50 & & \\
\hline \multirow{2}{*}{ Meridian group $(\mathrm{N}=8)$} & Pre-test & 56.00 & 4.47 & \multirow{2}{*}{2.565} & \multirow{2}{*}{$0.010^{*}$} \\
\hline & Post-test & 37.88 & 4.76 & & \\
\hline
\end{tabular}

M, mean; S.D., standard deviation; ${ }^{*} p<0.05$. 
Table 6. Stress analysis of post-effects of experimental group and comparison groups

\begin{tabular}{lccccc}
\hline Group & $\mathrm{M}$ & $\mathrm{SD}$ & $F$ & $p$-value & Bonferroni \\
Experimental group $(\mathrm{N}=8 ; \mathrm{a})$ & 26.38 & 4.80 & & \\
Counseling group $(\mathrm{N}=8 ; \mathrm{b})$ & 41.38 & 3.50 & 25.44 & $0.000^{* * *}$ & $\mathrm{a}<\mathrm{b}, \mathrm{c}$ \\
Meridian group $(\mathrm{N}=8 ; \mathrm{c})$ & 37.88 & 4.76 & & \\
\hline
\end{tabular}

M, mean; S.D., standard deviation; ${ }^{* * *} p<0.001$.

\section{Table 7. Analysis of observations of participant 'A' (Early level)}

\section{Behavioral observation}

As 'A' began to tell a story about her husband, her facial expression was dark, she had tears in her eyes, sometimes spoke loudly and, sometimes in a low trembling voice, with frequent pauses, and this continued for about $10 \mathrm{~min}$.

\section{Psychological analysis}

\section{Result analysis}

'A' was full of anger against her husband, due to the conflict between him and other family members.

Currently ' $A$ ' is taking care of her granddaughter. Because her daughter works. It was certain that 'A' was depressed. Because she was always tearful. This reflected her psychological depression.

\section{Table 8. Analysis of observation of consultation participant ' $A$ ' (Middle level)}

Behavioral observation

With a small, trembling voice, she said that she was too shy and ashamed to read her essay aloud. She appeared calm, and neat and tended to be highly principled, lacking in flexibility and having difficulty in dealing with things.

\section{Result analysis}

$$
\text { Psychological analysis }
$$

It appeared that she was apologizing to herself, as she red an essay of praise called "Mirror". As she read "Mirror" for the second time, her expression cleared up psychological change was observed.

\section{Daily life analysis}

The client complained that her whole body was unwell and she had no energy in her life to do anything, sometimes her anger grew, her chest felt stiff and her digestion was not good.

Table 9. Analysis of observations of consultation participant 'A' (Higher level)

\begin{tabular}{|c|c|c|}
\hline \multirow{2}{*}{ Behavioral observation } & \multicolumn{2}{|c|}{ Result analysis } \\
\hline & Psychological analysis & Daily life analysis \\
\hline $\begin{array}{l}\text { The participant's clothes and make-up were } \\
\text { brighter, which was taken as a positive signal } \\
\text { that life changes were happening. }\end{array}$ & $\begin{array}{l}\text { The participant had thought think about } \\
\text { new ways of living, writing in her journal } \\
\text { every session and saying "I can do it!" She } \\
\text { said that she felt that she was undergoing } \\
\text { positive changes in her life, and she } \\
\text { participated in every sessions of the singing } \\
\text { class. }\end{array}$ & $\begin{array}{l}\text { The participant observed that there had } \\
\text { been a change in her life. She feels positively } \\
\text { in that she now makes conversation with her } \\
\text { husband, and meeting the new people in the } \\
\text { singing class was helpful to her interpersonal } \\
\text { relationships, providing her energy in her life. }\end{array}$ \\
\hline
\end{tabular}

Table 10. Pre \& post analysis of experimental group

\begin{tabular}{|c|c|c|c|c|c|}
\hline Sub factor & Group & $M$ & SD & Z & $p$-value \\
\hline \multirow{2}{*}{ Evaluation of life } & Pre group $(\mathrm{N}=8)$ & 3.616 & 0.173 & \multirow{2}{*}{2.564} & \multirow{2}{*}{$0.011^{*}$} \\
\hline & Post group ( $\mathrm{N}=8$ ) & 3.233 & 0.138 & & \\
\hline \multirow{2}{*}{ Psychological symptom } & Pre group $(\mathrm{N}=8)$ & 3.555 & 0.157 & \multirow{2}{*}{2.527} & \multirow{2}{*}{$0.012^{*}$} \\
\hline & Post group $(\mathrm{N}=8)$ & 2.298 & 0.106 & & \\
\hline \multirow{2}{*}{$\begin{array}{l}\text { Defense mechanism and } \\
\text { correspondence strategy }\end{array}$} & Pre group $(\mathrm{N}=8)$ & 2.875 & 0.094 & \multirow{2}{*}{2.588} & \multirow{2}{*}{$0.010^{*}$} \\
\hline & Post group $(\mathrm{N}=8)$ & 2.000 & 0.066 & & \\
\hline \multirow{2}{*}{ Physical symptom } & Pre group $(\mathrm{N}=8)$ & 3.705 & 0.094 & \multirow{2}{*}{2.555} & \multirow{2}{*}{0.011} \\
\hline & Post group ( $\mathrm{N}=8$ ) & 2.566 & 0.082 & & \\
\hline
\end{tabular}

M, mean; S.D., standard deviation; ${ }^{*} p<0.05$. 


\section{3. 중년여성의 화병 완화의 초기, 중기, 후기 단계별 분석}

\section{1) 내담자 $A$ 초기단계}

초기단계는 1 회기에서 3 회기까지이며 내담자의 마음의 문을 열기 위한 단계이다. 상담자가 손 마사지를 시작하면서 "사랑 합니다.”라고 하는 말에 내담자는 깜짝 놀라는 것 같았으며, 내 담자 스스로에게 "oo야! 사랑한다.”라는 것을 해보라고 했을 때 내담자는 작은 목소리로 말을 하면서 쑥스러워 하였다. 이와 같은 방식으로 상담자는 내담자에게 심리적으로 접근하면서 인 간중심상담을 통해 내담자의 세계를 파악하기 위해 결혼생활에 서 느껴왔던 부정적인 감정을 마음껏 이야기하는 시간을 가졌 다. 가족 중 남편의 이야기를 시작하면서 표정이 어둡고 눈에 눈물이 고여 있었으며, 억양이 높기도 하고 낮은 목소리 떨림 도 있었으며, 중간 중간 물을 자주 마시며 $10 \mathrm{~min}$ 간 이야기하 는 것으로 보아 남편에게 화(불만)가 쌓였다는 것을 해석할 수 있었다. 초기단계에 나타난 이런 행동을 통해 자신보다는 가족 을 먼저 생각하고 살았는데 지금은 아무도 알아주지 않아서 섭 섭하고 억울하고, 화가 많은 삶을 살아 왔다는 것을 분석할 수 있었다(Table 7).

\section{2) 내담자 $A$ 중기단계}

중기단계는 4 회기에서 6 회기까지이며 내담자 자신의 마음속 에 내재된 의제화를 표현하여 심리적 정화와 개선을 경험하는 단계이다. 영상을 보고, 자신에게 칭찬의 글을 낭독하고 '누가 문제인가?’ 또 ‘나는 어떤 성격의 소유자인가?’라는 질문에 대 답해 보도록 하였다. 내담자는 '거울'이라는 칭찬의 글을 낭독 하지 못하고 한참 동안 글을 보면서 눈에 눈물이 고여 있다가 마침내 떨리는 목소리로 낭독을 하였다. 가족의 이야기를 하면 서 남편이 문제라고 생각을 했는데 문제는 자기 안에도 있다고 하였다. 자신이 감정표현을 잘 하지 못하고 참고만 있다 보니 이런 현상이 생겼다고 하였다(Table 8).

\section{3) 내담자 $A$ 후기단계}

후기단계는 7 회기에서 10 회기까지이며 내담자의 행동 취하 기로 긍정적 자기인식과 타인인식으로 변화계획을 실천하는 단 계이다. 새로운 변화의 삶의 실천 방안을 구상해 보면서 매 회 기마다 일기를 쓰고 긍정의 말을 낭독한 것이 도움이 되었다고 하였다. 노래교실에 결석하지 않고 가고 있으며, 남편과 이야 기하는 시간이 늘어나고 있다는 것은 긍정적인 이미지로 보였 다(Table 9).

\section{Conclusion}

본 연구에서는 미용심리치료 프로그램이 중년여성의 화병 완 화에 미치는 효과를 분석하고자 하였다. 프로그램 개발모형의 문헌연구를 고찰한 후 이를 토대로 문제점 및 제한점을 보완하 여 10 단계로 구성된 미용심리치료 프로그램 개발 모형에 맞추 어 이루어졌다. 프로그램 내용 절차는 미용관리사, 상담전문가 에게 프로그램의 목적과 내용에 대한 타당도를 근거로 수정 및 보완되었으며 예비 프로그램을 실시하여 효율성을 평가하고 내 담자의 피드백을 통해 수정 및 보완 절차를 거쳐서 최종 본 프 로그램으로 개발하였다.

첫째, 미용심리치료 프로그램의 화병 완화 효과와 관련하여 비교집단인 통합적 접근 상담, 미용경락집단 간에 사전보다는 사후의 편차가 증가했으나, 미용경락과 상담을 동시에 실시한 실험집단에서 사전과 사후 사이의 유의수준 $(p<0.05)$ 에서 차이 가 큰 것으로 나타났다.

둘째, 회기별 변화를 볼 때, 심리적 증상이 실험 전 보다 실 험 후 긍정적인 방향으로 변화되었으며, 방어기재 및 대응전략 의 경우 '삶에 대한 평가'에 있어서는 비교집단인 미용경락집단 과 통합적 접근 상담 집단간에 차이가 유의미하지 않았으나 실 험집단에서는 사전과 사후 사이의 유의한 차이가 있었다. 실험 집단과 미용경락집단의 화병 하위요인을 살펴보면 삶의 평가, 심리적 증상, 방어기제 및 대응전략이 사전과 사후 사이의 유 의 하다고 분석되었으며, 신체적 증상은 차이가 없는 것으로 나타났다. 실험집단과 상담집단의 화병 하위요인을 살펴보면 삶의 평가, 방어기재 및 대응전략에서 유의한 차이는 없으나, 심리적 증상과 신체적 증상은 사전과 사후 사이의 유의한 차이 가 있다고 나타났다. 미용경락집단과 통합적 상담집단의 화병 하위요인을 살펴보면 삶의 평가, 심리적 증상, 방어기제 및 대 응전략, 신체적 증상 모두 유의 하다고 분석되었으며 신체적 증상에서는 경락집단이 좀 더 유의 확률이 높다는 분석이 나왔 다(Table 10).

본 연구에서는 소수의 인원으로 진행되어 심리치료적인 효과 를 일반화시키기에는 다소 무리가 있지만 중년여성을 대상으로 한 사례 특성화에 더 중점을 주었기 때문에 매우 의미 있는 일 이라 사료된다. 향후 중년여성의 화병 완화에 효과적인 미용심 리치료 프로그램으로 활용할 수 있을 것이며, 후속적으로 중년 여성의 화병 완화를 위한 다양한 교육적 미용심리치료 프로그 램 연구가 이루어지길 기대한다. 


\section{References}

Chi SE, Kim JW, Whang WW, Cho HS. The study on the clinical aspects of Hwabyung patients. Journal of Oriental Neuropsychiatry, 8: 63-84, 1997.

Jo SY, Hwang SM. A study of effects of gap between actual age and self-perceived age in middle-age women on their appearance management behavior and selfesteem. Asian Journal of Beauty and Cosmetology, 11: 1137-1146, 2013.

Kim E, Nam HS, Kim TH. The moderating effect of marital satisfaction on the relation between wife's depression/ Hwa-byung and husband's depression/Hwa-byung. Journal of Korea Academia-Industrial cooperation Society, 10: 4837-4846, 2013.

Kim YG, Lee SH, Jeon BJ. Korean Hwa-byung: mental, cultural diagnosis and treatment. The Academy of Korean Studies, Seongnam, pp63-69, 1997.

Kwon JH, Choi KM. A validation study of the Korean marital satisfaction inventory. Korean Journal of Clinical Psychology, 18: 123-139, 1999.

Lee JY. The effect of women self-consciousness and selfmonitoring on their skincare behavior. Asian Journal of Beauty and Cosmetology, 11: 855-861, 2013.
Lim JH, Kim JW, Whang WW. A comparative study on the changes of the clinical appearances and stress perception of Hwabyung patients, according to the oriental medical therapy. Journal of Oriental Neuropsychiatry, 11: 47-57, 2000.

Min SK. A study of the concept of Hwabyung. Journal of the Korean Neuropsychiatric Association, 28: 604-616, 1989.

Min SK. Study of Hwa-byung. ML communications, Seoul, p10, 2009.

Park JS, Lyu YS. A bibliographic study about the meaning of Hwa and Hwa-byung. Journal of Oriental Neuropsychiatry, 8: 183-200, 1997.

Park YS, Chae SO. Literatures review in Hwabyung research. Journal of Korean Academy of Community Health Nursing, 12: 705-715, 2001.

Shin HS, Lee OJ. The literary study on the women's mental health and Hwabyung in Korean society. Journal of EastWest Nursing Research, 3: 68-82, 1998.

Yun SJ, Shin MH. The effect of back meridian massage on the muscle tension and body heat change of CLBP (chronic low back pain) middle-aged women's. Journal of the Korean Society of Cosmetology, 18: 771-776, 2012. 


\section{국문초록}

\section{미용심리치료 프로그램이 중년여성의 화병 완화에 미치는 효과}

방해주 , 최인혁

웨스트민스터신학대학원대학교 미용치료교육학, 경기도 용인시, 한국

목적: 본 연구는 중년여성의 화병을 감소시켜 삶의 만족감과 행복감 증진에 도움을 줄 수 있는 미용심리치료 프로그램의 효과를 검 증하는데 목적이 있다. 방법: 연구 대상은 $\mathrm{D}$ 지역에 거주하는 45-65세의 여성으로 참여 의사에 따라 동질성 검사 후 실험집단 및 두 개의 비교집단에 각각 8 명의 여성을 배정하였다. 이들을 대상으로 주 1 회, 매회기 $70 \mathrm{~min}$, 총 10 회를 실시하였다. 본 연구의 효과 는 비모수적 방법인 Kruskal-Wallis를 통해 검증하였고, 각 회기별로 행동변화를 관찰하였으며, 3개의 집단에 대한 효과 분석을 위 해, 일원배치분산분석(analysis of variance, ANOVA)을 실시하였다. 결과: 첫째, 미용심리치료 실시 후 중년여성의 화병 완화 효과 가 유의미한 차이를 보였다. 둘째, 회기별 변화를 볼 때 심리적 증상이 실험 전 보다 실험 후 긍정적인 방향으로 변화되었으며 방어 기재 및 대응전략의 경우 미래에 대한 긍정적인 생각이 증가하였다. 결론: 본 연구를 통해 미용심리치료 프로그램이 중년여성의 화 병 완화에 효과적임을 알 수 있었다.

핵심어: 미용심리치료, 중년여성, 화병, 경락마사지, 통합적 접근 상담

\section{참고문헌}

김열규, 이시형, 전병재. 한국인의 화병: 그 정신문화적 진단과 처방. 한국학중앙연구원, 성남, pp63-69, 1997.

김은하, 남현숙, 김태훈. 부인의 우울과 화병이 남편의 우울과 화병에 미치는 영향과 결혼 만족도의 조절 효과. 한국산학기술 학회논문지, 10: 4837-4846, 2013.

민성길. 화병연구. 엠엘커뮤니케이션, 서울, $\mathrm{p} 10,2009$.

민성길. 홧병(火病)의 개념에 대한 연구. 신경정신의학, 28: 604-616, 1989.

박영숙, 채선옥. 홧병 연구에 관한 고찰. 지역사회간호학회지, 12: 705-715, 2001.

박진성, 류영수. 화(火) 및 화병(火病)의 의의(意義)에 관한 문헌적(文獻的) 고찰(考察). 동의신경정신과학회지, 8: 183-200, 1997.

신혜숙, 이옥자. 여성의 정신장애와 홧병에 관한 문헌연구. 동서간호학연구지, 3: 68-82, 1998.

윤신중, 신명희. 등경락마사지가 CLBP (Chronic low back pain) 중년여성의 근 긴장도 및 체열변화에 미치는 영향. 한국미용 학회지, 18: 771-776, 2012.

이지영. 자기의식 및 자기검색이 성인여성의 피부관리행동에 미치는 영향. 아시안뷰티화장품학술지, 11: 855-861, 2013.

임재환, 김종우, 황의완. 한의학적(韓醫學的) 홧병 치료에 따라 나타나는 홧병 환자의 스트레스지각 정도와 임상양상(臨床樣 相)의 변화에 대한 비교연구(比較研究). 동의신경정신과학회지, 11: 47-57, 2000.

조선영, 황승민. 중년여성의 실제연령과 지각연령의 차이가 외모관리행동 및 자아존중감에 미치는 영향. 아시안뷰티화장품학

술지, 11: 1137-1146, 2013.

지상은, 김종우, 황의완, 조황성. 홧병환자의 임상양상에 대한 고찰. 동의신경정신과학회지, 8: 63-84, 1997. 


\section{中文摘要}

\section{美容心理治疗计划对缓解中年女性心火病的效果}

方海珠，崔仁赫

威斯敏斯特神学大学院大学校美容治疗教育学专业, 龙仁, 韩国

目的: 本研究的目的是通过缓解中年女性的心火病，为提高中年生活满足感和幸福感，开发和应用美容心理治疗计划， 并分析其效果。方法: 研究的对象是以D区域居住的45岁到65岁以下的女性，按照参与意向进行同质性检查后，分为实验 组、咨询组、经络按摩组, 每组各安排8名。每周1回, 每回70分, 总实施10回。本研究实行非参数方法 Kruskal-Wallis 验证, 每回进行实验后, 观察其行为改变。为确认实验后效果的差异分析, 并对其结果进行单向配置分散分析(analysis of variance, ANOVA)。结果: 第一，美容心理治疗计划实施后，缓解中年女性心火病的效果方面具有统计意义的差别。第 二, 从每一次的变化来看, 与实验前比较, 实验后的心理症状变为正向发展, 而且防御机制和对应战略方面呈现了对未 来肯定的思想变化。结论: 从以上研究中得出, 美容心理治疗计划对缓解中年女性的心火病方面具有效果。

关键词: 美容心理治疗, 中年女性, 心火病, 经络按摩, 综合接近方法 